\title{
Role of Taxanes in Triple-Negative Breast Cancer: A Study From Tertiary Cancer Center in South India
}

\author{
K.C. Lakshmaiaha, Abhishek Anand ${ }^{a}$, b , K. Govind Babu ${ }^{a}$, Lokanatha Dasappa ${ }^{a}$, \\ Linu Abraham Jacob ${ }^{a}$, Suresh Babu M.C. ${ }^{a}$, K.N. Lokesh ${ }^{a}$, A.H. Rudresha ${ }^{a}$, L.K. Rajeev ${ }^{\text {, }}$ \\ Smitha C. Saldanha ${ }^{a}$, G.V. Giria ${ }^{\text {, Deepak Koppaka }}{ }^{a}$
}

\begin{abstract}
Background: Breast cancer is the most common female cancer seen globally. Triple-negative breast cancer (TNBC) is a special subtype without any obvious target and optimum treatment remains challenging. The aim was to study the clinical, pathological profile and treatment outcome of TNBC patients.
\end{abstract}

Methods: This was a retrospective observational study of TNBC patients diagnosed from January 2010 to June 2012 at a tertiary cancer center in South India. Patient's clinical and pathological characteristics were studied. The 5-year estimate of survival for non-metastatic TNBC was done using the Kaplan-Meier method.

Results: Out of 804 patients of breast cancer, 237 were diagnosed as TNBC. The median age was 45 years and $58 \%$ were premenopausal. The 5-year disease-free survival (DFS) and overall survival (OS) for non-metastatic TNBC patients were 59\% and 74\%, respectively. The addition of a taxane to anthracycline-based regimen did not show a significant difference in DFS $(\mathrm{P}=0.885)$ as well as OS $(\mathrm{P}=0.856)$.

Conclusion: The role of adding taxanes to anthracycline-based chemotherapy in adjuvant setting for TNBC remains controversial and larger prospective studies are warranted.

Keywords: Triple-negative breast cancer; Taxane

\section{Introduction}

Breast cancer is the second most common cancer and, the most common cancer among women worldwide [1]. In India, breast

Manuscript submitted June 23, 2017, accepted July 25, 2017

aDepartment of Medical Oncology, Kidwai Memorial Institute of Oncology, Bangalore 560029, India

${ }^{b}$ Corresponding Author: Abhishek Anand, Department of Medical Oncology, Kidwai Memorial Institute of Oncology, Dr. M H Marigowda Road, Bangalore 560029, India. Email: drabhishek2508@gmail.com

doi: https://doi.org/10.14740/wjon1054w cancer is now the most common cancer in most cities, and second most common in the rural areas after cervical cancer [2]. The biological behavior is considered to be heterogenous and dramatically different outcomes can be seen in patients with similar clinicopathological features [3, 4]. The gene expression profiling has divided breast cancer into five different subtypes: luminal A, luminal B, normal breast-like, human epidermal growth factor receptor 2 (HER2/neu)-overexpressing, and basal-like [5, 6]. Triple-negative breast cancer (TNBC) is a special subtype which lacks the expression of estrogen receptor (ER), progesterone receptor (PR) and HER2 [7-10]. TNBC accounts for $10-20 \%$ of all breast cancers worldwide [11, 12]. Tumors with this subtype usually present in younger women and considered to have aggressive behavior with early development of recurrence and distant metastasis [13]. There is no guideline specific to TNBC and in clinical practice surgery combined with chemotherapy is the most effective treatment [14-16]. The present study was done to analyze treatment outcome of TNBC patients.

\section{Methods}

This was a retrospective observational study done at a tertiary cancer center in South India. Case files of all patients with breast cancer coming to the Department of Medical Oncology from January 2010 to June 2012 were reviewed. TNBCs were selected for the study and follow-up data were taken from the medical record. Those not coming for regular examination after treatment were contacted telephonically. The diagnosis of TNBC was made when the tumor was negative for ER, PR, and HER2. A score of 1 - 2 on Allred score [9] was taken negative for hormone receptor, whereas a score of 0 or 1 by IHC was considered negative for HER2. For those having a score of $2+$ on IHC for HER2 further confirmation was done by fluorescence in situ hybridization (FISH). The staging was done according to AJCC-7. For disease-free survival (DFS) and overall survival (OS) analysis, patients with stage I-III disease were taken. DFS and OS estimations were the main objectives of the study. The time from diagnosis to the development of clinical or radiological metastatic disease or to the last follow-up without disease was taken for DFS, whereas time from diagnosis to time of death was defined for OS analysis. 
Table 1. Patient Characteristic and Treatment Received

\begin{tabular}{|c|c|c|}
\hline & $\mathrm{n}=\mathbf{2 3 7}$ & $\%$ \\
\hline Median age (years) & \multicolumn{2}{|c|}{45 (range $22-85$ ) } \\
\hline \multicolumn{3}{|l|}{ Menopausal status } \\
\hline Premenopausal & 138 & 58 \\
\hline Postmenopausal & 99 & 42 \\
\hline \multicolumn{3}{|l|}{ Stage } \\
\hline I & 6 & 2.5 \\
\hline II & 98 & 41.3 \\
\hline III & 112 & 47.3 \\
\hline IV & 21 & 8.9 \\
\hline \multicolumn{3}{|l|}{ Histology } \\
\hline Invasive ductal carcinoma & 229 & 96.6 \\
\hline Metaplastic & 5 & 2.1 \\
\hline Medullary & 3 & 1.3 \\
\hline \multicolumn{3}{|l|}{ Grade } \\
\hline I & 0 & 0 \\
\hline II & 33 & 13.9 \\
\hline III & 204 & 86.1 \\
\hline \multicolumn{3}{|l|}{ Surgery for stage I-III } \\
\hline Yes & 203 & 94.0 \\
\hline No & 13 & 6.0 \\
\hline \multicolumn{3}{|l|}{ Chemotherapy (NACT or adjuvant) } \\
\hline Yes & 178 & 87.7 \\
\hline No & 25 & 12.3 \\
\hline \multicolumn{3}{|l|}{ Regimen used } \\
\hline Anthracycline-based & 85 & 47.8 \\
\hline Anthracycline + taxane-based & 93 & 52.2 \\
\hline \multicolumn{3}{|c|}{ Pattern of metastasis ( $n=70$; out of 178 patients evaluated) } \\
\hline Loco-regional & 27 & 38.6 \\
\hline Lung & 22 & 31.4 \\
\hline Liver & 14 & 20.0 \\
\hline Brain & 8 & 11.4 \\
\hline Bone & 23 & 32.9 \\
\hline
\end{tabular}

NACT: neoadjuvant chemotherapy.

\section{Data analysis}

All available data were analyzed using IBM SPSS software version 23.0. Kaplan-Meier survival analysis was done for DFS and OS. Log-rank test was applied for comparing survival of different chemotherapy regimens (anthracycline and anthracycline + taxane). A P-value of less than 0.05 was taken as significant.

\section{Results}

\section{Patient characteristics}

Out of 804 patients with breast cancer seen during the period of 2.5 years, $237(29.5 \%)$ were diagnosed as TNBC. The me- dian age was 45 years (range 22 - 85 years). Fifty-eight percent of TNBC patients were premenopausal at the time of diagnosis. Twenty-one patients were metastatic at the time of initial presentation and were not included in the survival analysis. Pathological examination revealed invasive ductal carcinoma in 229 tumors. Five tumors were metaplastic and three of medullary type. Grade III disease was seen in $86 \%(n=204)$ of the patients with rest $(n=33)$ being grade II. No patient was diagnosed with grade I tumor. Patient clinicopathological profiles are shown in Table 1.

\section{Treatment outcome}

Eighteen patients (13 non-metastatic and five metastatic) did not receive any kind of treatment after diagnosis due to poor 


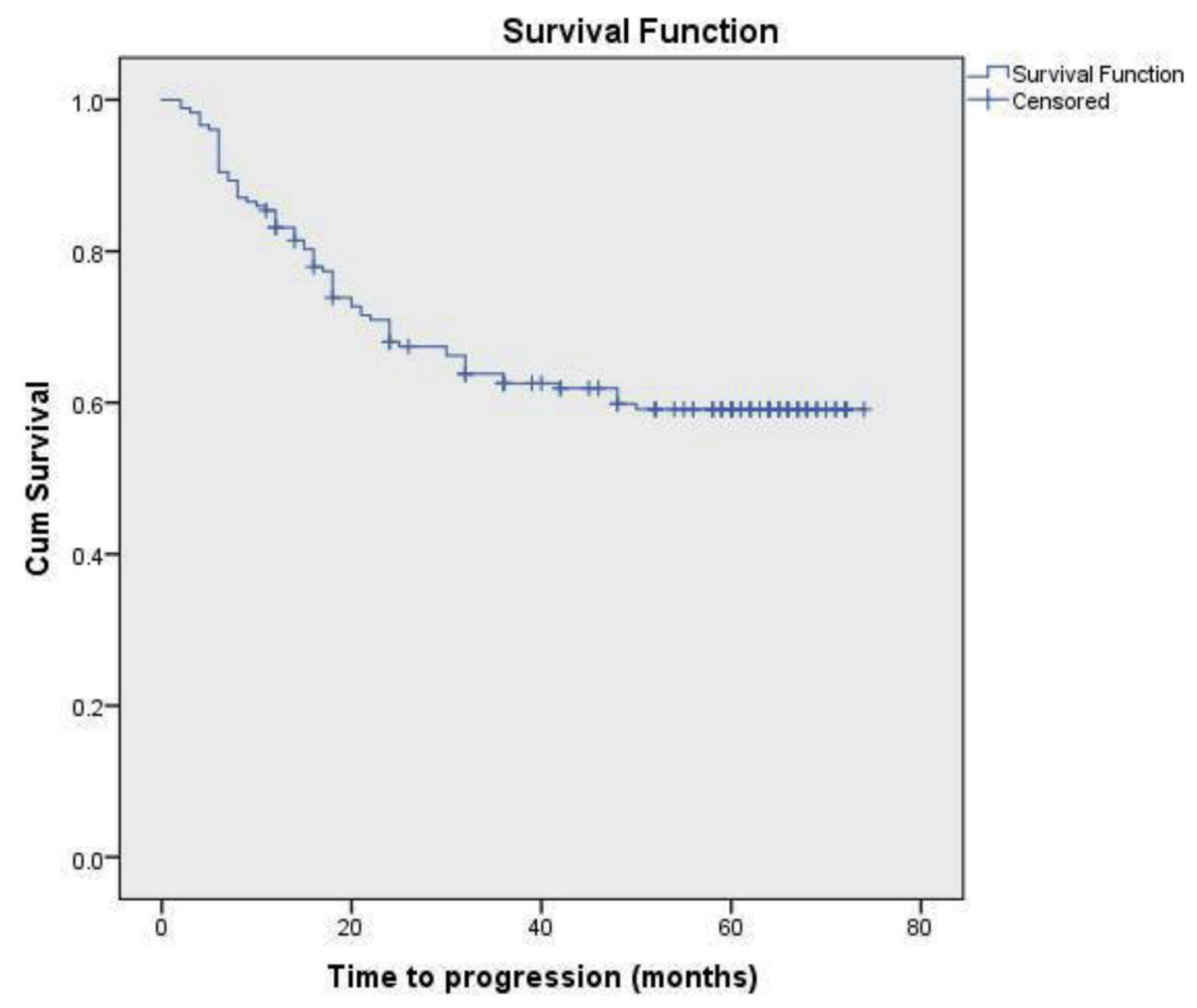

Figure 1. DFS in patients with TNBC $(n=178)$.

performance status or patient refusal. Among non-metastatic patients, surgery was done for 203 patients. Chemotherapy either in neoadjuvant or adjuvant setting was given to 178 patients. Radiation therapy was given as per the indication and institute protocol. Patients who received chemotherapy in either neoadjuvant and/or adjuvant setting $(n=178)$ were evaluated for survival outcomes. Anthracycline-based regimen was given to 85 patients, whereas 93 patients received anthracycline in combination with taxane. The 5-year DFS and OS were 59\% and 74\%, respectively. On comparison of anthracycline vs. anthracycline + taxane-based regimen, no significant difference in DFS $(\mathrm{P}=$ $0.885)$ as well as OS $(\mathrm{P}=0.856)$ was found. The Kaplan-Meier survival analyses have been shown in Figure 1 (DFS in patients with TNBC $(\mathrm{n}=178)$ ), Figure 2 (OS in patients with TNBC (n $=178$ ), Figure 3 (DFS comparison of anthracycline-based vs. anthracycline + taxane-based regimen), and Figure 4 (OS comparison of anthracycline-based vs. anthracycline + taxane-based regimen). Out of 70 patients with recurrence, loco-regional was the most common pattern seen in 27 patients. Among visceral metastasis, lung was the most common site observed in 22 patients. Bone metastasis was seen in 23 patients, whereas eight patients had disease recurrence in the brain. More than one site of metastasis at recurrence was seen in 24 patients with lung and liver metastasis presenting together in 11 patients.

\section{Discussion}

Of all breast cancer subtypes, TNBC comprises $10-20 \%$ with a slightly lower incidence in western countries [17-19]. The highest incidence of TNBC (up to 30\%) is among the AfricanAmericans and Hispanic white women [20-22]. There may be an association of genetic or biological differences and environmental factors leading to the difference in incidence [23, 24]. In the present study, the incidence of TNBC was $29.5 \%$ $(237 / 804)$ which is higher than that reported from the west. The median age of TNBC is 50 years and most are premenopausal at the time of diagnosis [25]. In our study, the median age was 45 years and $58 \%$ were premenopausal.

Other than invasive ductal carcinoma, metaplastic, medullary, adenoid cystic and apocrine carcinomas are the common histological subtypes seen in TNBC [26]. Also, the tumor usually is high grade which is related to the poor prognosis associated with TNBC. We found five tumors of metaplastic and three medullary subtypes, rest being invasive ductal carcinoma. Most tumors (86\%) were grade III. The clinical and pathological characteristics are in concordance with another study published from our institute by Lakshmaiah et al [27].

An early peak of recurrence between the first and third year after diagnosis followed by a sharp decrease of disease relapse in subsequent years is characteristic of TNBC [28]. When compared to other breast cancer subtypes, metastases in TNBC tend to be more aggressive than other and more likely to occur in the viscera, particularly in the lungs and brain [29]. Bone involvement is less commonly seen [30]. A study done by Rakha et al [19] of 1,994 patients with breast cancer reported a 5 -year DFS of $67 \%$ vs. $82 \%$ among TNBC and nonTNBC patients. A study by Yuan et al [31] showed a 5-year 


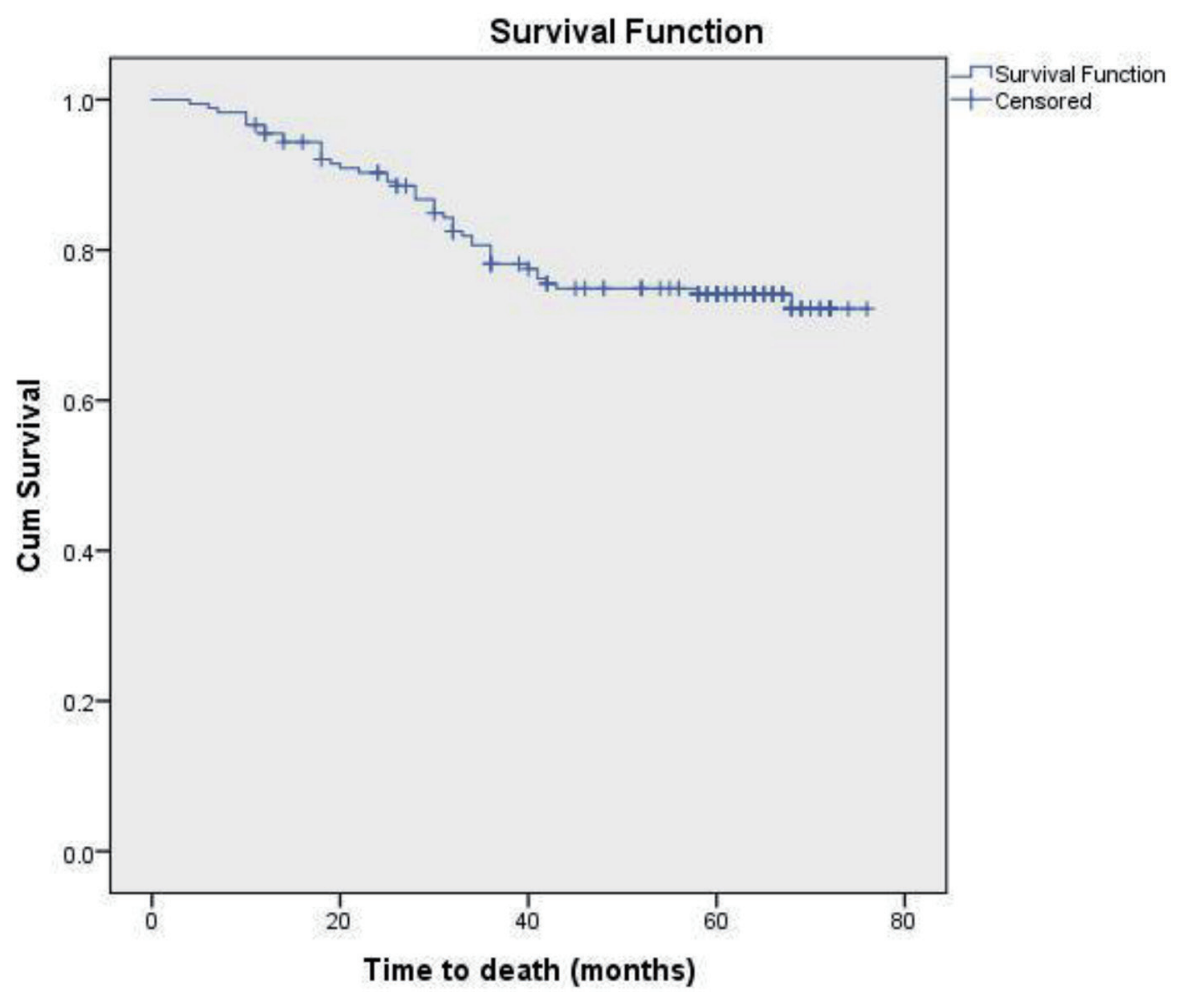

Figure 2. OS in patients with TNBC $(n=178)$.

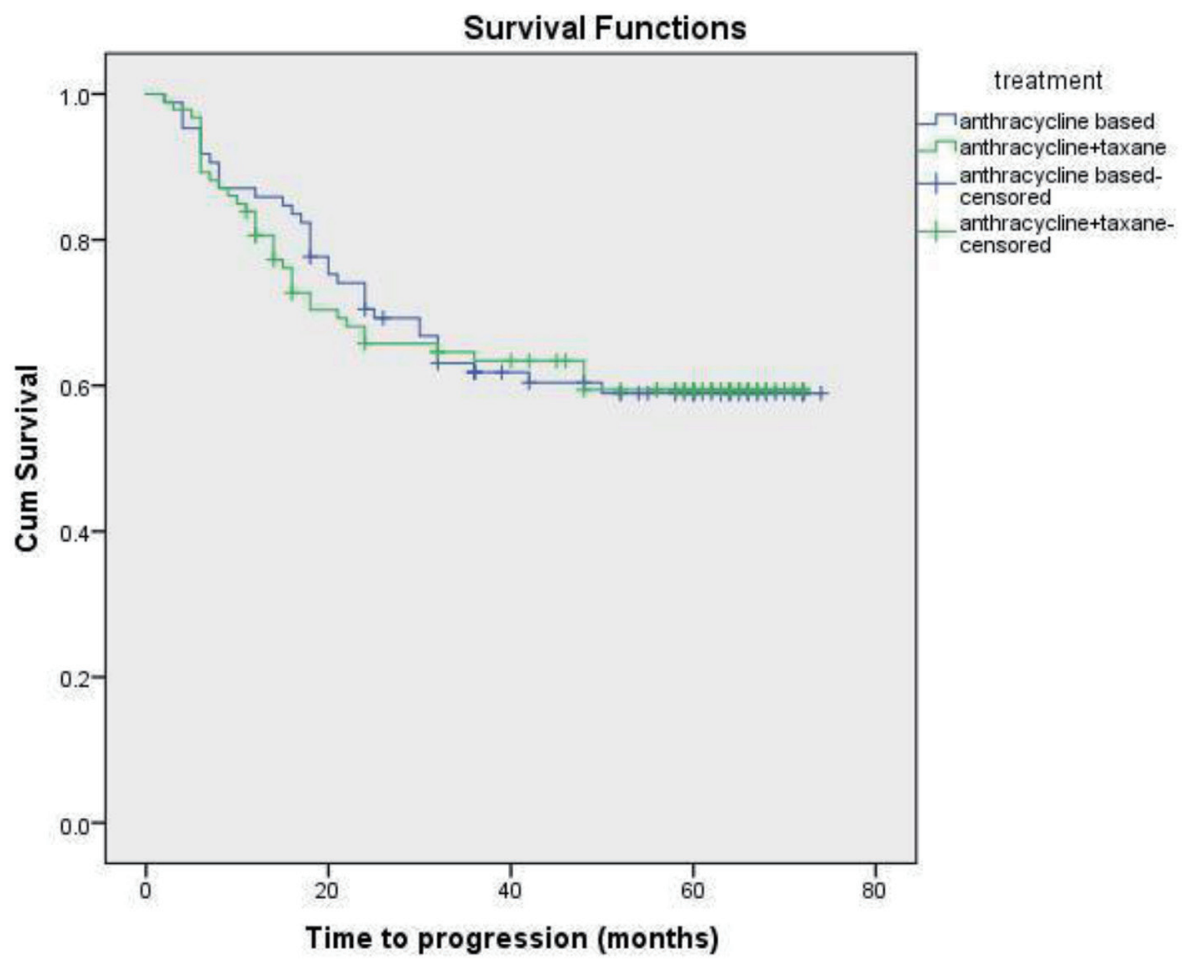

Figure 3. DFS comparison of anthracycline vs. anthracycline + taxane-based regimen. 


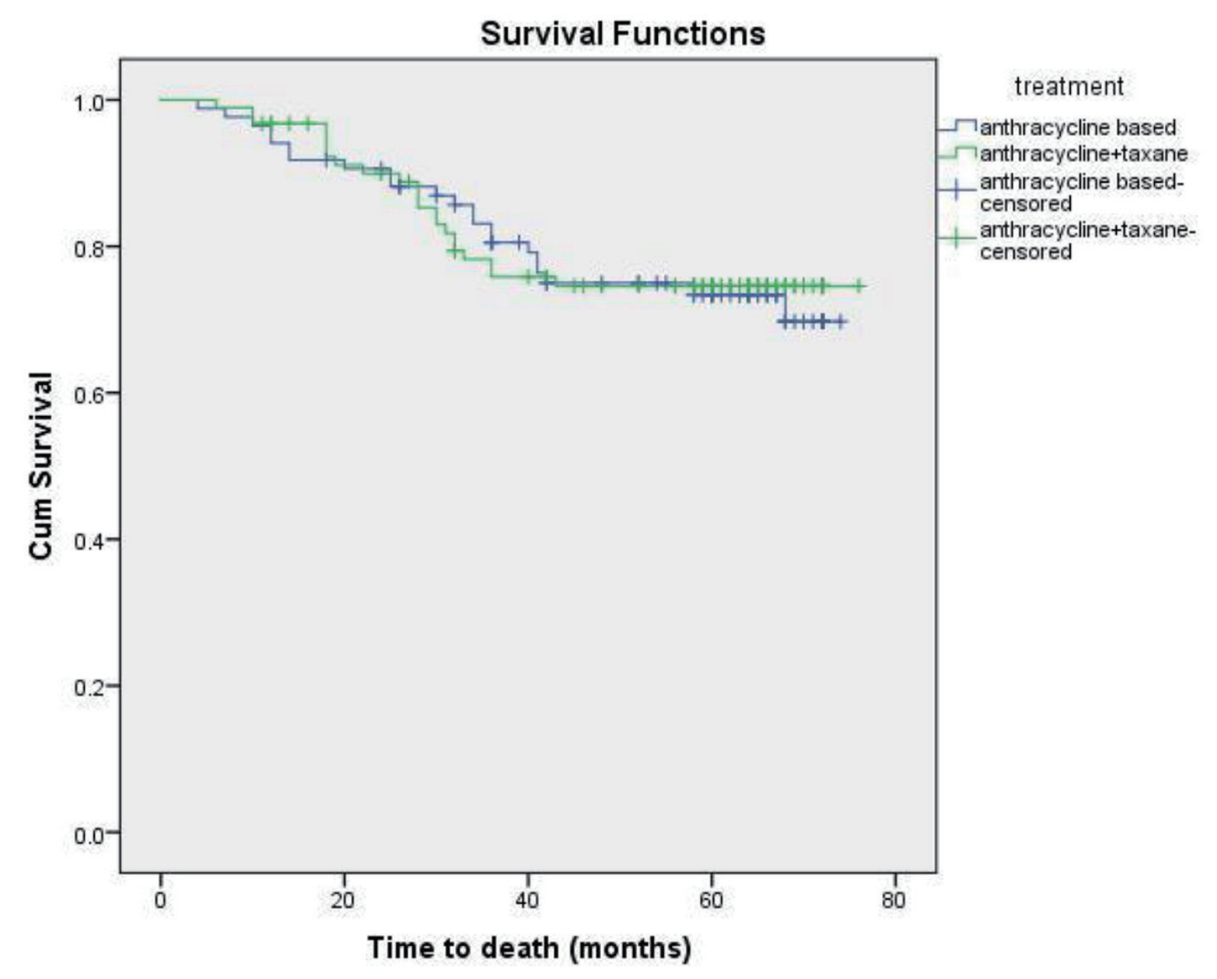

Figure 4. OS comparison of anthracycline vs. anthracycline + taxane-based regimen.

DFS rate of $73.7 \%$ vs. $80.8 \%$ among patients with TNBC vs. non-TNBC, respectively. The corresponding 5-year OS was $88.5 \%$ vs. $92.8 \%$, respectively. Similarly, Haffty et al showed poorer outcome in TNBC cohort with a 5-year DFS of $67 \%$ vs. $82 \%$ for non-TNBC [32]. In our study, the 5-year DFS and OS were $59 \%$ and $74 \%$, respectively, which is comparable to other studies.

Local, as well as distant recurrence is commonly seen within 1 - 3 years in TNBC. A study done by Dent et al [12] showed the incidence of distant metastasis was significantly higher in TNBC as compared to non-TNBC. After a long follow-up, they observed a peak in second and third year, followed by a rapid decline in the recurrence rate. The incidence of metastasis to lung liver and brain was higher than of nonTNBC cohort. Similar findings were reported by Lin et al [33] and Rakha et al [19]. In our study, locoregional recurrence was the most common pattern of relapse. Among visceral recurrence, lung was the most common site followed by liver and brain. In contrast to the literature, the incidence of bone metastasis was higher in the present study.

As TNBC lacks obvious target, there remains a challenge in the optimum treatment strategy. These patients are at higher risk of early relapse, although chemotherapy is associated with a more favorable outcome as compared to other subtypes [28, 30]. Although the addition of taxanes to adjuvant anthracyclinebased regimen has been evaluated in various studies, the results in patients with TNBC are limited and a preferential benefit of microtubule-stabilizing agents has not been clearly demonstrated. The beneficial effect of the addition of taxane has been suggested by subset analysis of several large trials. A meta-analysis of 12 randomized clinical trials demonstrated that adjuvant docetaxel-based chemotherapy is associated with an improvement in DFS and OS in TNBC compared with regimens without taxanes [34]. Unplanned subset analysis of three retrospective studies of adjuvant chemotherapy trials coordinated by CALGB and the US Breast showed a statistically significant improvement in DFS with the addition of paclitaxel therapy $(\mathrm{P}=0.002)$, whereas ER+ HER2(-) individuals did not experience a similar benefit ( $P$ $=0.71$ ), thereby supporting the inclusion of taxanes in adjuvant therapy for the treatment of patients with TNBC [35]. The additional benefit of taxanes, however, has not been shown consistently in various other trials of TNBC. There was no significant difference in TNBC patients with the addition of docetaxel in the TACT trial [36]. Similar findings were observed when FEC was compared with epirubicin plus docetaxel in PACS-004 trial [37]. In the present study, the differences in the DFS and OS with regards to anthracycline or anthracycline plus taxanesbased chemotherapy were not statistically significant either in DFS $(\mathrm{P}=0.885)$ or $\mathrm{OS}(\mathrm{P}=0.856)$.

The poor prognosis of TNBC has been associated with the aggressive behavior as well as lack of targeted therapy against this entity. Although anthracycline in combination with taxanes has been the standard chemotherapy, the exact benefit of addition of taxanes remains to be determined. Recent efforts in optimizing the treatment of TNBC have found promising results with platinum agents and poly ADP-ribose polymerase 1 (PARP) inhibitors. BRCA1 dysfunction in TNBC has been associated with increased sensitivity of these agents and trials are underway evaluating their role in the adjuvant settings [3]. Other novel therapeutic targets for TNBC include epidermal 
growth factor receptor (EGFR), c-Kit; mitogen-activated protein (MAP)-kinase pathway; and Akt pathway [38]. Therefore, more focus on newer treatment modalities based on different prognostic markers like BRCA gene status, androgen receptors, and basal cytokeratin expression is warranted.

\section{Conclusion}

TNBC is an aggressive subtype with a higher incidence among young premenopausal women. These are associated with higher grade of the tumor, early peak of metastasis to visceral organs and poor prognosis. Addition of taxanes to anthracyclinebased regimens did not have a survival benefit when compared to anthracycline-based regimens.

\section{Conflicts of Interest}

The authors declare that there are no actual or potential conflicts of interest in relation to this article.

\section{References}

1. GLOBOCAN 2012 [database on the Internet]. Geneva, World Health Organisation, 2015. http://globocan.iarc.fr/ Pages/fact_sheets_cancer.aspx.

2. ICMR Cancer Registry 2004: Consolidated Reports of the PBCR and HBCR's. ICMR; 2001 2003. p. 13.

3. Gluz O, Liedtke C, Gottschalk N, Pusztai L, Nitz U, Harbeck N. Triple-negative breast cancer - current status and future directions. Ann Oncol. 2009;20(12):1913-1927.

4. Podkrajsek M, Zgajnar J, Hocevar M. What is the most common mammographic appearance of T1a and T1b inasive breast cancer? Radiol Oncol. 2008;42:173-180.

5. Sorlie T, Perou CM, Tibshirani R, Aas T, Geisler S, Johnsen H, Hastie T, et al. Gene expression patterns of breast carcinomas distinguish tumor subclasses with clinical implications. Proc Natl Acad Sci U S A. 2001;98(19):1086910874.

6. Sorlie T, Tibshirani R, Parker J, Hastie T, Marron JS, Nobel A, Deng S, et al. Repeated observation of breast tumor subtypes in independent gene expression data sets. Proc Natl Acad Sci U S A. 2003;100(14):8418-8423.

7. Tang Y, Xu F, Tao K, Qian N, Toi M. Clinical applications of sentinel lymph node biopsy in ductal carcinoma in situ of the breast: a dilemma. Tohoku J Exp Med. 2011;224(1):1-5.

8. Bidard FC, Conforti R, Boulet T, Michiels S, Delaloge S, Andre F. Does triple-negative phenotype accurately identify basal-like tumour? An immunohistochemical analysis based on 143 'triple-negative' breast cancers. Ann Oncol. 2007;18(7):1285-1286.

9. Hammond ME, Hayes DF, Dowsett M, Allred DC, Hagerty KL, Badve S, Fitzgibbons PL, et al. American Society of Clinical Oncology/College Of American Pathologists guideline recommendations for immunohistochemical testing of estrogen and progesterone receptors in breast cancer. J Clin Oncol. 2010;28(16):2784-2795.

10. Goldhirsch A, Wood WC, Coates AS, Gelber RD, Thurlimann B, Senn HJ, Panel m. Strategies for subtypes - dealing with the diversity of breast cancer: highlights of the St. Gallen International Expert Consensus on the Primary Therapy of Early Breast Cancer 2011. Ann Oncol. 2011;22(8):1736-1747.

11. Dent R, Trudeau M, Pritchard KI, Hanna WM, Kahn HK, Sawka CA, Lickley LA, et al. Triple-negative breast cancer: clinical features and patterns of recurrence. Clin Cancer Res. 2007;13(15 Pt 1):4429-4434.

12. Rakha EA, Tan DS, Foulkes WD, Ellis IO, Tutt A, Nielsen TO, Reis-Filho JS. Are triple-negative tumours and basal-like breast cancer synonymous? Breast Cancer Res. 2007;9(6):404; author reply 405.

13. Rakha EA, Ellis IO. Triple-negative/basal-like breast cancer: review. Pathology. 2009;41(1):40-47.

14. Isakoff SJ. Triple-negative breast cancer: role of specific chemotherapy agents. Cancer J. 2010;16(1):53-61.

15. Rodler E, Korde L, Gralow J. Current treatment options in triple negative breast cancer. Breast Dis. 2010;32(12):99-122.

16. Carey L, Winer E, Viale G, Cameron D, Gianni L. Triplenegative breast cancer: disease entity or title of convenience? Nat Rev Clin Oncol. 2010;7(12):683-692.

17. Nielsen TO, Hsu FD, Jensen K, Cheang M, Karaca G, $\mathrm{Hu} \mathrm{Z}$, Hernandez-Boussard T, et al. Immunohistochemical and clinical characterization of the basal-like subtype of invasive breast carcinoma. Clin Cancer Res. 2004;10(16):5367-5374.

18. Banerjee S, Reis-Filho JS, Ashley S, Steele D, Ashworth A, Lakhani SR, Smith IE. Basal-like breast carcinomas: clinical outcome and response to chemotherapy. J Clin Pathol. 2006;59(7):729-735.

19. Rakha EA, El-Sayed ME, Green AR, Lee AH, Robertson JF, Ellis IO. Prognostic markers in triple-negative breast cancer. Cancer. 2007;109(1):25-32.

20. Trivers KF, Lund MJ, Porter PL, Liff JM, Flagg EW, Coates RJ, Eley JW. The epidemiology of triple-negative breast cancer, including race. Cancer Causes Control. 2009;20(7):1071-1082.

21. Dolle JM, Daling JR, White E, Brinton LA, Doody DR, Porter PL, Malone KE. Risk factors for triple-negative breast cancer in women under the age of 45 years. Cancer Epidemiol Biomarkers Prev. 2009;18(4):1157-1166.

22. Huo D, Ikpatt F, Khramtsov A, Dangou JM, Nanda R, Dignam J, Zhang B, et al. Population differences in breast cancer: survey in indigenous African women reveals over-representation of triple-negative breast cancer. J Clin Oncol. 2009;27(27):4515-4521.

23. Huan Y and Lu CL. Progression for triple-negative breast cancer. Chinese Journal of Current Advances in General Surgery. 2010;13:726-729.

24. Ozkan M, Berk V, Kaplan MA, Benekli M, Coskun U, Bilici A, Gumus M, et al. Gemcitabine and cisplatin combination chemotherapy in triple negative metastatic breast cancer previously treated with a taxane/anthracycline chemotherapy; multicenter experience. Neoplasma. 2012;59(1):38-42. 
25. Cai MQ, Chen Q, Shi CM. Progression for triple-negative breast cancer. Chinese Clinical Oncology. 2009;14:286287.

26. Criscitiello C, Azim HA, Jr., Schouten PC, Linn SC, Sotiriou C. Understanding the biology of triple-negative breast cancer. Ann Oncol. 2012;23(Suppl 6):vi13-18.

27. Lakshmaiah KC, Das U, Suresh TM, Lokanatha D, Babu GK, Jacob LA, Babu S. A study of triple negative breast cancer at a tertiary cancer care center in southern India. Ann Med Health Sci Res. 2014;4(6):933-937.

28. Blows FM, Driver KE, Schmidt MK, Broeks A, van Leeuwen FE, Wesseling J, Cheang MC, et al. Subtyping of breast cancer by immunohistochemistry to investigate a relationship between subtype and short and long term survival: a collaborative analysis of data for 10,159 cases from 12 studies. PLoS Med. 2010;7(5):e1000279.

29. Heitz F, Harter P, Lueck HJ, Fissler-Eckhoff A, LorenzSalehi F, Scheil-Bertram S, Traut A, et al. Triple-negative and HER2-overexpressing breast cancers exhibit an elevated risk and an earlier occurrence of cerebral metastases. Eur J Cancer. 2009;45(16):2792-2798.

30. Liedtke C, Mazouni C, Hess KR, Andre F, Tordai A, Mejia JA, Symmans WF, et al. Response to neoadjuvant therapy and long-term survival in patients with triple-negative breast cancer. J Clin Oncol. 2008;26(8):1275-1281.

31. Yuan ZY, Wang SS, Gao Y, Su ZY, Luo WB, Guan ZZ. [Clinical characteristics and prognosis of triple-negative breast cancer: a report of 305 cases]. Ai Zheng. 2008;27(6):561-565.

32. Haffty BG, Yang Q, Reiss M, Kearney T, Higgins SA, Weidhaas J, Harris L, et al. Locoregional relapse and dis- tant metastasis in conservatively managed triple negative early-stage breast cancer. J Clin Oncol. 2006;24(36):56525657.

33. Lin NU, Claus E, Sohl J, Razzak AR, Arnaout A, Winer EP. Sites of distant recurrence and clinical outcomes in patients with metastatic triple-negative breast cancer: high incidence of central nervous system metastases. Cancer. 2008;113(10):2638-2645.

34. Laporte S, Jones S, Chapelle C, Jacquin J, Martin M. Consistency of effect of docetaxel containing adjuvant chemotherapy in patients with early stage breast cancer independent of nodal status: metaanalysis of 12 randomized clinical trials. Cancer Res. 2009;69(Suppl 1):Abstr 605 .

35. Hayes DF, Thor AD, Dressler LG, Weaver D, Edgerton S, Cowan D, Broadwater G, et al. HER2 and response to paclitaxel in node-positive breast cancer. N Engl J Med. 2007;357(15):1496-1506.

36. Ellis P, Barrett-Lee P, Johnson L, Cameron D, Wardley A, O'Reilly S, Verrill M, et al. Sequential docetaxel as adjuvant chemotherapy for early breast cancer (TACT): an open-label, phase III, randomised controlled trial. Lancet. 2009;373(9676):1681-1692.

37. Roche H, Allouache D, Romieu G, Bourgeois H, Canon J, Serin D, et al. Five-year analysis of the FNCLCC-PACS04 Trial: FEC100 vs. ED75 for the adjuvant treatment of node positive breast cancer. Cancer Res. 2010;69:24s abstract 60 .

38. Cleator S, Heller W, Coombes RC. Triple-negative breast cancer: therapeutic options. Lancet Oncol. 2007;8(3):235244. 